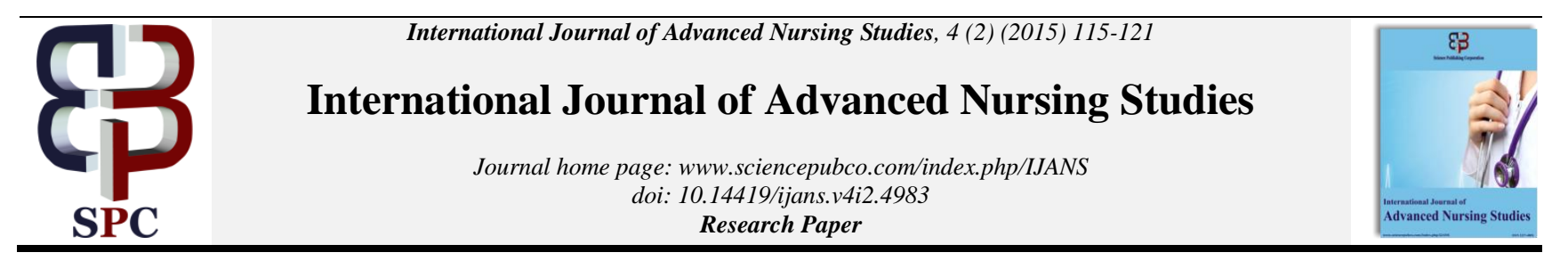

\title{
Implementation of reflective practice programme for registered nurses
}

\author{
Lucia N. Nelumbu \\ University of Namibia, Private Bag 13301, Windhoek; Namibia \\ E-mail: Inelumbu@unam.na
}

\begin{abstract}
The researcher was convinced that the development of a programme is the good idea that will enhance the proper application of reflective practice in clinical settings for nurses not simply to perform daily routine activities without paying attention to reflection. The developed programme was implemented through a two-day workshop. Therefore, the researcher considered the workshop to be an ideal strategy for implementation, because reflection can only be facilitated and practiced through active participation. The participants were drawn from various disciplines such as: Paediatrics, Surgery, Gynecology and Obstetrics and Internal Medicine. The facilitator explained the purpose of the workshop and the rules to be followed during the workshop. The content of the programme was presented and discussed during the specific sessions as it was scheduled. After the sessions, the participants were informed that they have to go back and apply what they learned from the workshop during their clinical practice for three months. And after three months the facilitator together with the participants contacted the evaluation of the application of the content of the programme.
\end{abstract}

Keywords: Implementation; Application.

\section{Introduction}

This article is extracted from the author's study, "An Educational programme to facilitate reflective practice for registered nurses in training hospitals in Windhoek. The author was convinced that the development of a reflective practice programme would enhance the proper application of reflective practice in clinical settings by the registered nurses and prevent them from performing daily activities simply as a routine without engaging into reflection. This was also justified by the responses gained from the participants, who showed little insight into the concept of reflective practice, as they only expressed the execution of their daily activities without paying attention to how they reflect in daily practice.

\section{The purpose}

The purpose of the implementation was to offer knowledge and skills to effectively address the clinical challenges which the registered nurses may encounter in terms of reflection, and to encourage them to develop reflection in order to deliver quality patient and nursing care.

\section{The process of implementation of reflective practice programme}

The developed programme was implemented through a two-day workshop. A workshop is a strategy with teaching and learning that is structured in small groups to enhance active participation (Tiberius \& Silver, 2001). Traditionally, workshops provided participants with some opportunity to practice skills and receive feedback. Therefore, the researcher considered the workshop to be an ideal strategy for implementation, because reflection can only be facilitated and practiced through active participation.

The initial stage for the implementation of the programme included the planning of the two-day workshop. During planning the researcher collaborated with all relevant stakeholders by explaining the outcome of the findings of the study and obtaining permission to conduct the workshop with the registered nurses. The researcher compiled a workshop agenda entailing all aspects related to the developed programme. The researcher invited the registered nurses as participants from both training hospitals in Windhoek through their supervisors. The participants were drawn from various disciplines such as: Paediatrics, Surgery, Gynecology and Obstetrics and Internal Medicine.

A specific schedule for the implementation of the developed programme was developed, the phases of training and sessions of the workshop are displayed in Table 1 below.

Table 1: Outlined Programme Phases and Sessions for the Workshop

\begin{tabular}{|c|c|}
\hline & Day 1 \\
\hline Introductory phase & Session 1 \\
\hline - Introduction & - Welcoming and introduction of \\
\hline - Know each other & the workshop \\
\hline $\begin{array}{l}\text { - Explanation of the purpose } \\
\text { of the }\end{array}$ & $\begin{array}{l}\text { - Purpose and objectives of the } \\
\text { workshop }\end{array}$ \\
\hline Programme & $\begin{array}{l}\text { - Rules of the workshop if applica- } \\
\text { ble }\end{array}$ \\
\hline Active phase & Session 2 The concept of reflection \\
\hline Focus of the workshop- & Session 3 \\
\hline reflective practice cycle into & - Kolb's experiential learning \\
\hline nursing process: & - Rolfe's reflective practice frame- \\
\hline - Kolb's experiential learning & work \\
\hline - Rolfe's three stages of & Session 4 \\
\hline reflective practice & - Nursing process \\
\hline - Nursing process & $\begin{array}{l}\text { Session } 5 \\
-\quad \text { Conclusion }\end{array}$ \\
\hline
\end{tabular}

Copyright $\odot 2015$ Lucia N. Nelumbu. This is an open access article distributed under the Creative Commons Attribution License, which permits unrestricted use, distribution, and reproduction in any medium, provided the original work is properly cited. 


\begin{tabular}{lll}
\hline & Day 2 \\
Active phase continue & Day two activities \\
$\begin{array}{l}\text { Focus of the workshop- } \\
\text { reflective practice cycle into }\end{array}$ & $\begin{array}{l}\text { Rolfe's reflective practice framework } \\
\text { nursing process: }\end{array}$ & in Nursing process \\
$\bullet \quad$ Integration of reflec- & $\bullet$ & Session 2 Scenario (group \\
tive practice in nursing process & work) & \\
Scenario (group work) & $\bullet$ & Evaluation of the workshop \\
& $\bullet$ & Closing \\
\hline
\end{tabular}

Day 1

\section{Session 1: orientation}

Participants were welcomed, after which they introduced themselves to each other. In order to create a good atmosphere and to put the participants at ease, the facilitator has started the workshop with a prayer, after which the participants were provided in the programme schedule. The researcher explained the purpose of the workshop and the rules to be followed during the workshop.

Rules of the training workshop were set by the facilitator and the participants as follows:

- No one's idea is responded to negatively; everyone should respect others because we are all here to share and learn.

- Everyone can speak without interruption from others.

- Time for sessions should be adhered to.

Before the facilitator commenced, the participants were asked to share their opinions on the concept of reflective practice. Some of the answers provided were:

- "To go into the already existing practice or process and see whether new theories cannot be applied to better theories or processes."

- "The type of service you give (poor or good), so will be the outcome."

- "Looking back at the past."

- "Reflection of your mind on daily things that happen."

- "Refer to revise back or to check what you had already done and do some improvement on it.'

- "I think it is to my mind."

- "It's all about how we apply our nursing practice."

- "Reviewing on teaching and practicing of nursing to give quality nursing care."

- "Refreshing your mind to new concepts of nursing practice (nursing process).

- "Your thought of mind about something."

- "Is a reflection of your actions, for example if you do your work properly, you will get good job satisfaction as well as your employer and patients."

- "It is an ongoing process of looking back or reflecting one's mind after a certain activity (practice) is carried out."

In light of the above responses it can be deduced that the general understanding of registered nurses on reflective practice needs to be uplifted.

The facilitator proceeded with the presentation of the reflective practice programme. The programme was offered by means of power point presentation, role play and group discussions. During the workshop, the facilitator played an important role in facilitating the presentation, and discussion processes. The facilitator set clear objectives for each session, and logical structures were followed according to the specific concepts.

\section{The content of the programme}

\subsection{Session 2: definition of the concept "reflection" re- flection}

Reflection is defined as a process of reviewing one's repertoire of clinical experience and knowledge to invent novel approaches to complex clinical problems. Reflection also provides data for selfevaluation and increases learning from experience. It is further defined as a process of reviewing an experience of practice in order to describe, analyse, evaluate and so inform learning about practice (Bulman \&Schutz, 2004; Bulman \&Schutz, 2008).

Reflection can also be seen as an integral part of practice to which registered nurses need to have a commitment in order to develop such important skills. To do this, registered nurses should think of an experience at the moment and go through it so that they can get insight into ways in providing solutions to different situations. ROLE PLAY on reflection

An example was used from the clinical environment. The participants demonstrated on how to communicate with the patient suffering from terrible cough.

\subsection{Session 3: reflective models and frameworks of re- flection}

\subsubsection{Experiential learning cycle}

Experiential learning is defined by Quinn and Hughes (2007, p. 33 ) as "learning by doing, rather than by listening to other people or reading about it."

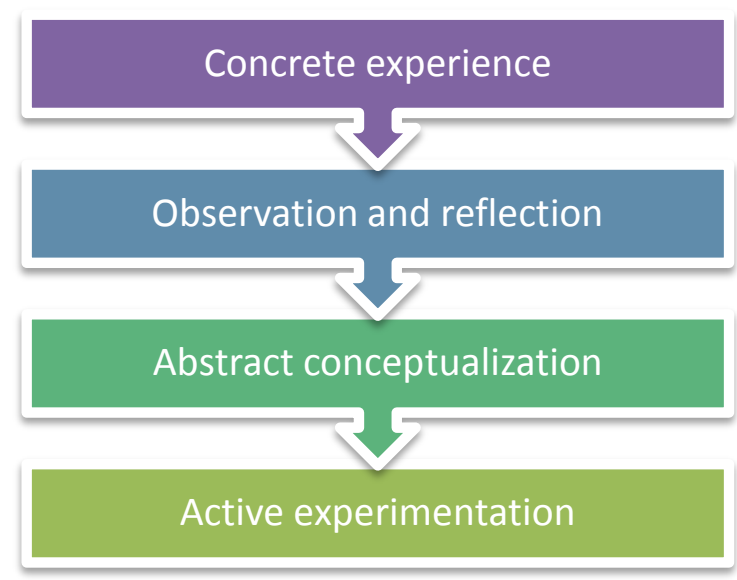

Fig. 1: Kolb's Reflective Practice: an Experiential Learning Cycle.

\subsubsection{Objectives}

After this session the participants will be able to:

- Interpret the meaning of Kolb's experiential learning cycle;

- Describe the experiential learning cycle content;

- Interpret Rolfe's reflective practice framework;

- Discuss the content of Rolfe's framework.

\subsubsection{Concrete experience}

This level is based on an inquiry concerning something which happened.

It focuses on the identification of the problems of practice. At this level registered nurses are experiencing personal challenges and are involved deeply in thoughts about the specific challenges. The registered nurses should also be concerned about something or an activity she/ he has done.

Smith (2001) argued that the use of concrete experience refers to the testing of ideas and the use of feedback to change practice and theories.

\subsubsection{Reflection}

Reflection exists to provide guidance and help registered nurses to look back over challenges or events which happened, to review them and change them into learning experiences. 


\subsubsection{Conceptualisation}

This level provides that learners such as registered nurses should make an appropriate decision by using the concepts so that they can make a conclusion from past and present experience. This involves the ability to construct a plan of action to address the problems. According to Kolb (1984), learners (registered nurses) should be able to develop concepts that enable them to integrate their observations into useful theories.

\subsubsection{Experimentation}

Registered nurses are now at the stage where they can plan, and apply the new learning from the previous experiences. Registered nurses might also try and record an event where they are aware of reflecting in action, then also apply retrospective reflection to the same events.

Smith (2001) explained that experimentation was well understood because it is based on application through action in a new circumstance within a range of generalisation. This means that action is taking place in a different set of circumstances, and the learner is now able to anticipate the possible effects of the action.

\section{Rolfe's model of reflective practice}

\subsection{Definition}

Reflective practice is understood as a process of learning and development through examining one's own practice, including experiences, thoughts, feelings, actions and knowledge (Bolton, 2005, cited in Bulman \& Schutz, (2008).

\subsection{Description of the content of Rolfe' framework}

What-A description of the event; led by the following trigger questions:

- What happened?

- What did I see/do?

- What did the other people do who were involved in this?

So what-An analysis of the event, led by the following questions:

- How did I feel at the time of the event?

- Do I feel troubled or uncertain?

- What positive reflection emerged after the event that happened in practice?

- What observations does any person helping me to reflect on my practice?

Now what-Proposed actions following the event described and analysed, led by the following questions:

- What are the implications for me and others in clinical practice, based on what I have?

- Where can I get more information to face a similar situation again?

- How could I modify my practice?

- Which aspect should be tackled first?

- What is the learning I take from reflecting on my practice?

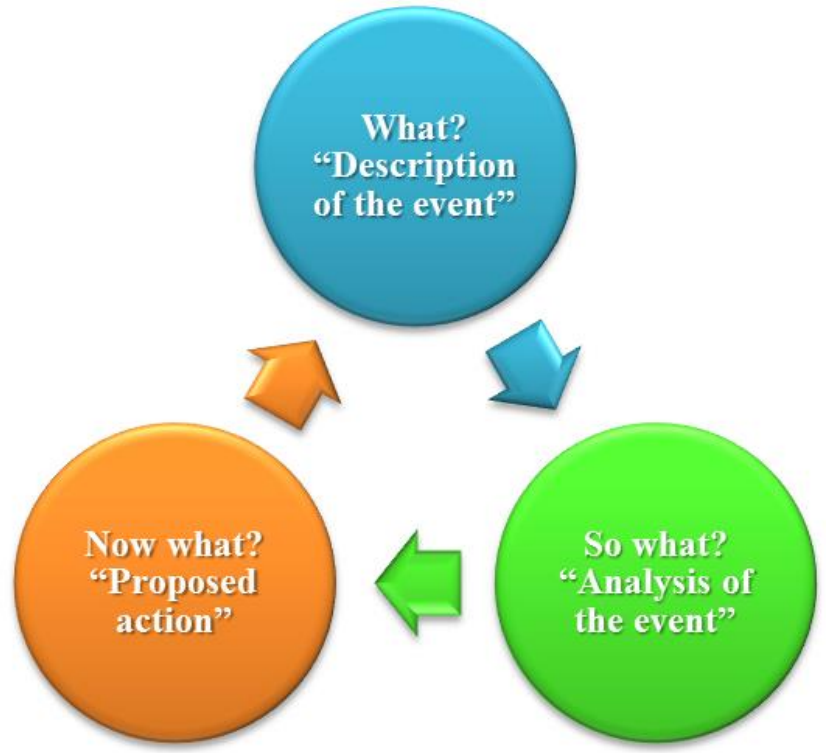

Fig. 2: Rolfe's Reflective Practice Cycle.

\section{Session 4: nursing process}

\subsection{Definition}

The nursing process refers to the relationship or interaction between a patient and a nurse.

The nursing process consists of the following five components: assessment, planning, implementation, evaluation and record keeping.

\subsection{Objectives}

After this session the participants will be able to:

- Define nursing process and

- Discuss the levels of nursing process.

\subsection{Assessment}

Assessment comprises the following aspects:

- The identification of different needs of patients.

- Identification of patients' behaviour associated with unexpressed needs.

- Assessment of the presence of a need and its effects on the patient.

- Recording of patients' needs.

\subsection{Planning}

Planning should focus on the following:

- Prioritising of the patient's needs, deciding which needs urgent attention;

- Assessing the presence of a need and its effects on the patient and

- Planning to meet the need which is the highest on the priority list.

\subsection{Implementation}

Implementation should indicate how the knowledge and skills are applied to solve problems. This is the implementation of the plan.

\subsection{Evaluation}

Evaluation involves an in-depth analysis of the plan concentrating on the following:

- Evaluation of the success or failure of the plan and 
- Strategies of re-planning in case of the failure of the original planning.

\subsection{Record keeping}

Records and recording are essential elements of reflective practice. Registered nurses should decide what to keep. These records should reflect the quality of their clinical role. Recap of Day 1 activities including Session 1 to Session 4 objectives.

\section{Session 5: conclusion}

To conclude the previous sessions the relationship between Kolb's cycle, Rolfe's reflective framework and Nursing process is displayed in Figure 6.3 and table 1below:

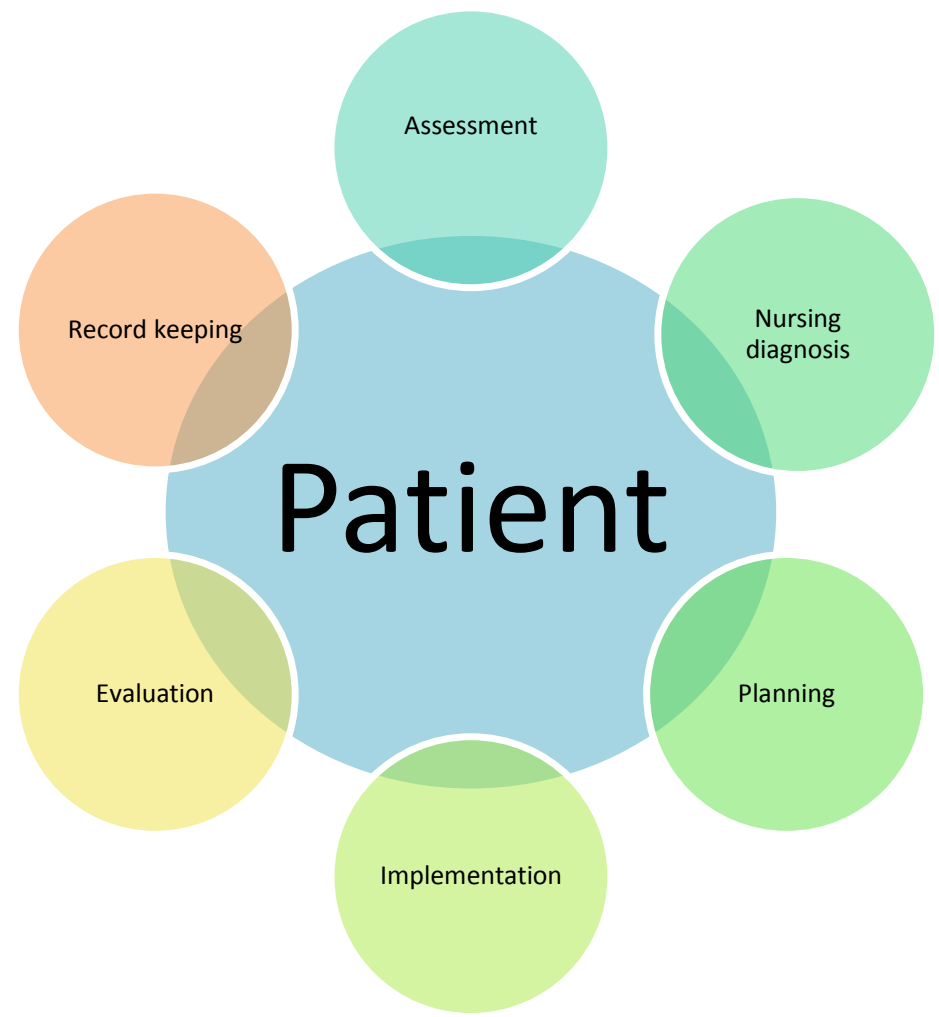

Fig. 3: The Nursing Process Diagram.

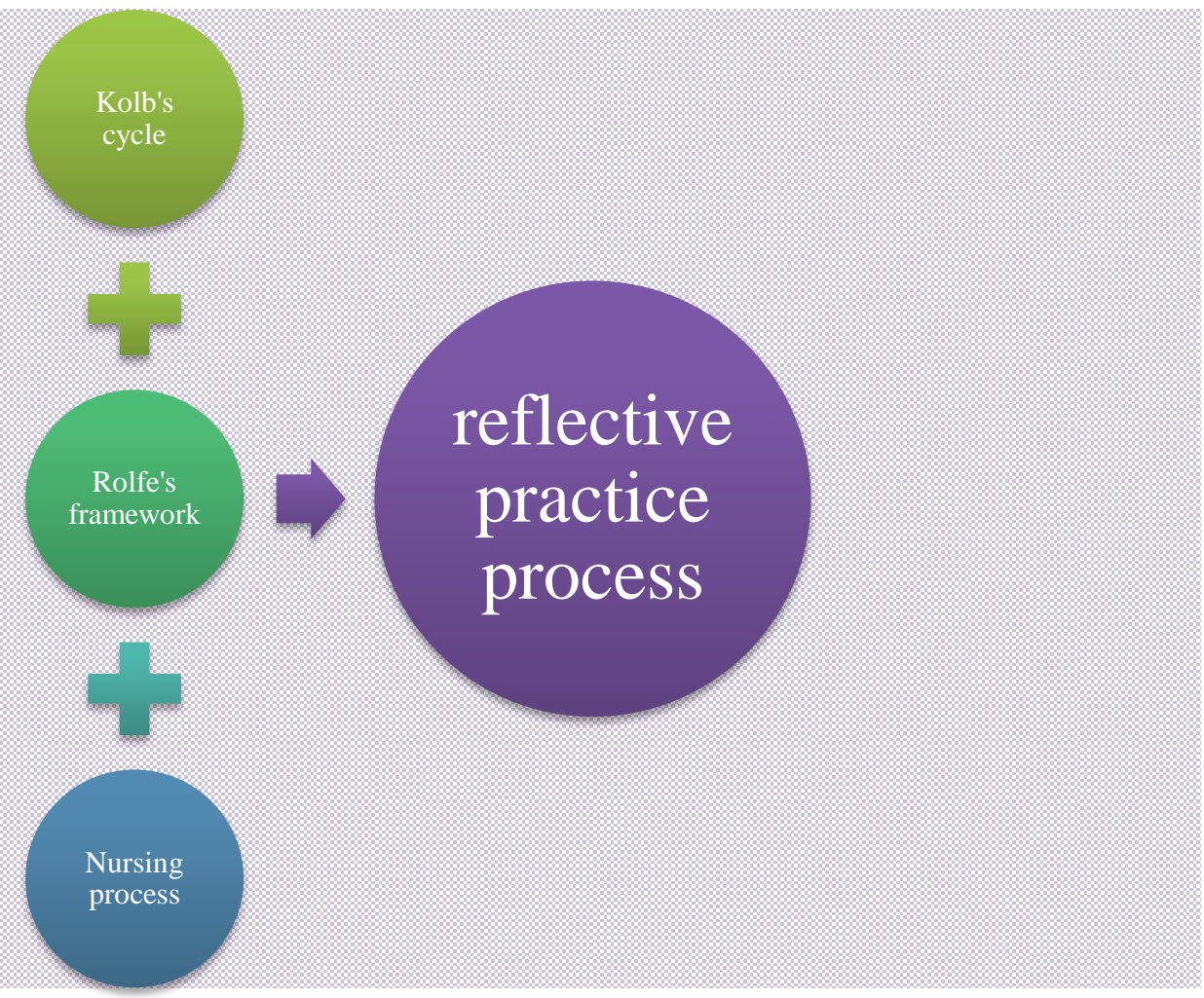

Fig. 4: Relationship between Kolb's Cycle, Rolfe's Reflective Framework and Nursing Process. 
Table 2: The Relationship of the Content of the Programme: Nursing Process, Kolb's Cycle and Rolfe's Framework.

\begin{tabular}{|c|c|c|}
\hline Nursing Process & Kolb's Cycle & Rolfe's Framework \\
\hline $\begin{array}{l}\text { Assessment of a } \\
\text { patient; history tak- } \\
\text { ing, physical exami- } \\
\text { nation }\end{array}$ & $\begin{array}{l}\text { Concrete experience: } \\
\text { focus on identification } \\
\text { of problems }\end{array}$ & $\begin{array}{l}\text { What happened? What } \\
\text { do I see? }\end{array}$ \\
\hline Nursing diagnosis & $\begin{array}{l}\text { Observation and re- } \\
\text { flection: consolidation }\end{array}$ & $\begin{array}{l}\text { How is my relation- } \\
\text { ship to the patient? } \\
\text { How to resolve the } \\
\text { situation? }\end{array}$ \\
\hline $\begin{array}{l}\text { Planning: planning of } \\
\text { nursing care }\end{array}$ & $\begin{array}{l}\text { Ability to construct a } \\
\text { plan of action: nursing } \\
\text { care plan }\end{array}$ & What action do I take? \\
\hline Implementation & $\begin{array}{l}\text { Transformation of the } \\
\text { developed concepts, } \\
\text { actions in new situa- } \\
\text { tions }\end{array}$ & $\begin{array}{l}\text { What did I base my } \\
\text { actions on? What other } \\
\text { knowledge to solve the } \\
\text { problem? }\end{array}$ \\
\hline Evaluation & $\begin{array}{l}\text { Evaluate whether the } \\
\text { actions were success- } \\
\text { ful }\end{array}$ & $\begin{array}{l}\text { Possible consequenc- } \\
\text { es. What could I have } \\
\text { done better? }\end{array}$ \\
\hline Record keeping & Record keeping & Record keeping \\
\hline
\end{tabular}

\section{Session 6: integration of Rolfe's reflective practice framework in nursing process}

\subsection{Introduction}

The nursing process, as described previously, can be improved when integrated with Rolfe's framework of reflective practice. The researcher noticed that it is appropriate to integrate Rolfe's framework in the existing nursing process in order to enhance reflection among registered nurses. This integrated process consists of six stages which are guided by Rolfe's trigger questions of reflection: "What?", "So what?", and "Now what?"

\subsection{Objectives}

- Importance of integration of Rolfe's framework in nursing process

- Applying the integrated framework into practice

Day 2

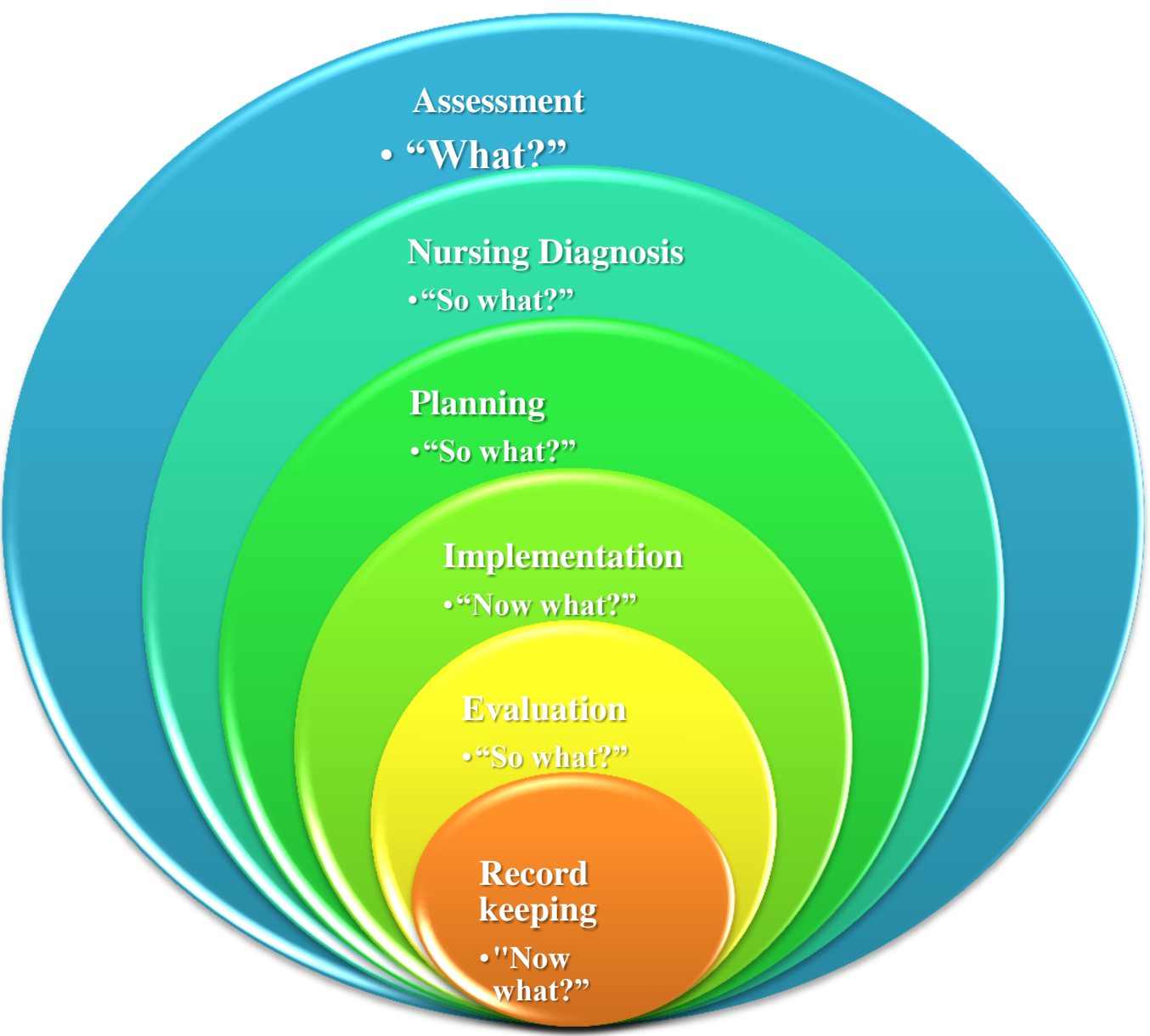

Fig. 5: Nursing Process and Rolfe's Reflective Practice Framework. 
Table 3: Integration of Rolfe's Reflective Practice Framework in the Nursing Process

\begin{tabular}{|c|c|}
\hline Nursing process: & Rolfe's reflective practice framework: \\
\hline Assessment: & What? \\
\hline $\begin{array}{l}\text { An example from practice: } 52- \\
\text { year-old man suffering from } \\
\text { stress. On day two, observation } \\
\text { shows BP of } 150 / 120 \text {. }\end{array}$ & $\begin{array}{l}\text { Ask yourself about the experience. } \\
\text { What happened? What are factors con- } \\
\text { tributing to this problem (physiological } \\
\text { and other, for example,psychological or } \\
\text { social)? }\end{array}$ \\
\hline Nursing Diagnosis: & So what? \\
\hline $\begin{array}{l}\text { Stress due to psychological } \\
\text { problems }\end{array}$ & $\begin{array}{l}\text { What would be my role as a registered } \\
\text { nurse concerning the meaning of this } \\
\text { experience? Do I have adequate } \\
\text { knowledge about this experience? What } \\
\text { kind of care is my patient looking for? }\end{array}$ \\
\hline Planning: & So what? \\
\hline $\begin{array}{l}\text { Explain the problem to the } \\
\text { patient. Develop the nursing } \\
\text { care plan. Involve the doctor. } \\
\text { Have the prescription in place } \\
\text { according to the doctor's order. } \\
\text { Prepare the environment-for } \\
\text { example, a quiet and relaxing } \\
\text { warm room. }\end{array}$ & $\begin{array}{l}\text { Whom else do I have to involve? What } \\
\text { have I learnt about this experience? } \\
\text { What else I can think of as a solution to } \\
\text { this problem? What action, based on } \\
\text { my patient's and the family's feelings } \\
\text { and needs? If I act in this way what } \\
\text { would happen to my patient? }\end{array}$ \\
\hline Implementation: & Now what? \\
\hline $\begin{array}{l}\text { Do observation: Blood pres- } \\
\text { sure should be monitored } \\
6 \text { hourly. Position of the patient } \\
\text { and position of the cuff. Accu- } \\
\text { rate readings. Medication } \\
\text { should be given as prescribed. } \\
\text { Proper counselling }\end{array}$ & $\begin{array}{l}\text { What else could I do? What do I need } \\
\text { to do in order to improve my patient's } \\
\text { care? What might be the outcome of my } \\
\text { action? }\end{array}$ \\
\hline Evaluation: & So what? \\
\hline $\begin{array}{l}\text { Does the treatment work or } \\
\text { not? Is the problem addressed } \\
\text { and improved? }\end{array}$ & $\begin{array}{l}\text { What have I learned about this experi- } \\
\text { ence? What knowledge and skills have I } \\
\text { gained? What more do I need to know } \\
\text { about this? }\end{array}$ \\
\hline Record keeping: & Now what? \\
\hline $\begin{array}{l}\text { Recording of the activities } \\
\text { performed }\end{array}$ & $\begin{array}{l}\text { What do I need to do after my actions? } \\
\text { What do I need to change for next time? }\end{array}$ \\
\hline
\end{tabular}

After the explanation of the content of the integrated process the researcher presented the scenario to the participants in order for them to reflect.

This was an example for a teaching moment during the workshop. The participants were advised to think of any example from their respective clinical environment for application.

\section{Session 7: Small group activities}

\subsection{Scenario}

Mrs. Black visits the casualty department with her 6-month old baby girl. The baby looks very ill and tired. The baby's weight is $5 \mathrm{~kg}$ and is suffering from diarrhea for 4 days. The weight taken 3 months back was $4.5 \mathrm{~kg}$. The last immunization (DPT \& Polio) was given after ten (10) weeks.

\subsection{Objectives}

After this session the participants will be able to:

- Analyse the given scenario accordingly and reflectively and

- Demonstrate knowledge in the application of reflective practice in their daily practice.

\subsection{Instructions}

- Analyse the scenario in light of the integrated framework of Rolfe in nursing process. Indicate how you would apply the result of your analysis to a similar situation in your daily practice.

The researcher opted for this method because simulated learning through the utilisation of clinical scenarios enables the development of conceptual understanding through problem solving of real world issues (Wiseman \& Horton (2011).

\subsection{Expectations from the analysis of the scenario}

These were presented as a guide after the group activities in order to compare their works.

Assessment:

- Consciousness level,

- Vital signs,

- Dehydration level through skin pinch, dry mucosa and compare weight for age,

- HIV status, and

- Immunisations and if Vitamin A supplements have been started.

Nursing diagnosis:

- Weight loss, diarrhoea, immunisation not update

- Plan:

- Rehydration

- Breastfeeding

- Immunisation

- Referral if needed

Implementation:

- Oral rehydration solution according to the degree of dehydration, or intravenous therapy;

- Health education on breastfeeding up to two years of age, referral when necessary.

Evaluation:

- Follow-up when necessary and in 5 days.

Record:

- All the information and treatment should be recorded.

\subsection{Reflection on the scenario}

- Reflection should be done by assessing the degree of dehydration. The registered nurses aim at identifying loss of body fluid, hypovolemia and the risk for shock.

- By assessing consciousness level the registered nurses aim at ruling out the loss of essential electrolytes and acidosis. By assessing the vital signs the registered nurses aim at ruling out the risk for subnormal vitals, for example heart arrest due to loss of electrolytes or low body temperature due to low metabolism from acidosis.

- By assessing weight the registered nurses aim at identifying growth default.

- By assessing and investigate HIV to rule out possible motherto-child transmission, hence the risk of diarrhoea diseases.

- By giving health education on breastfeeding to ensure sufficient breastfeeding up to age 2 and supplemental feeding, since the baby is now 6 months old. The importance of immunisation the diseases the child can get if not immunised.

\section{Conclusion}

This article has stipulated the purpose andobjectives of the implementation of the programme.The process of implementation of the reflective practice programme was also outlined based on the key components of the programme such as the Nursing process, Kolb's experiential learning cycle and Rolfe's reflective practice framework.The scenario was also presented with the aim of stimulating learning experience of the registered nurses through reflection process. The registered nurses who participated in the training of the programme were deeply committed to the discussions. They have been motivated and were aware of their own responsibility for the improvement of their practice with regard to 
the application of reflective practice.The participants of the workshop on the implementation of the reflective practice programme were required to evaluate the proceedings. They concurred that the objectives of the workshop were clear and its content was relevant to the nursing practice.

\section{Acknowledgements}

This article was written and extracted from the study conducted by the author as "An educational programme to facilitate reflective practice of registered nurses in training hospitals in Windhoek with the permission of the Ethical and Research Committee of the Ministry of Health and Social Services in Namibia. Special thanks are extended to all the registered nurses who participated in this implementation of the programme for making themselves available in spirit of sharing their experiences and perceptions on the important concept which is reflective practice which lead to the improvement of provision of nursing care to the patients.

\section{References}

[1] Bulman, C. \&Schutz, S. (2004). Reflective practice in nursing. Oxford: Blackwell Publishing.

[2] Bulman, C. \&Schutz, S. (2008). Reflective practice in nursing. Oxford: Blackwell Publishing.

[3] Kolb, D. A. (1984).Experiential learning: Experience as the source of learning and development. New Jersey: Prentice Hall.

[4] Quinn, F.M. \& Hughes S.J. (2007).Quinn's Principles and Practice of Nurse Education, Cheltenham: Nelson Thornes.

[5] Smith, M.K. (2001). 'David A. Kolb on experiential learning', the encyclopedia of Informal Education.Retrieved 12January 2012 from http://www.infed.org/b-explrn.htm.

[6] Tiberius, R. \& Silver, I. (2001).Guidelines for conducting workshops and seminars.Retrieved on 26 September 2011 from www.hsc.wvu.edu.

[7] Wiseman, A. \& Horton, K. (2011).Developing clinical scenarios from a European perspective: Successes and challenges, Nurse Education Today, 31(7), 677-781. http://dx.doi.org/10.1016/j.nedt.2011.01.001. 